\title{
Soil Organic Matter: a sustainability indicator for wildfire control and bioenergy production in the urban/forest interface
}

\author{
Juan A. Blanco ${ }^{\mathrm{a}, 1}$, David Dubois ${ }^{\mathrm{b}}$, Dale Littlejohn ${ }^{\mathrm{c}}$, David N. Flanders ${ }^{\mathrm{d}}$, Peter Robinson ${ }^{\mathrm{c}}$, Molly \\ Moshofsky $^{\mathrm{a}}$, Clive Welham ${ }^{\mathrm{a}}$
}

${ }^{a}$ Dep. Forest Sciences, University of British Columbia, 2424 Main Mall, Vancouver, BC, V6T1Z4, Canada

${ }^{\mathrm{b}}$ Wood Waste to Rural Heat Project, c/o Community Futures East Kootenay, 110A Slater Road NW, Cranbrook, BC, V1C 5C8, Canada

${ }^{\mathrm{c}}$ Community Energy Association, 3324 - 2260 West Mall, University of British Columbia, Vancouver, BC, V6T1Z4, Canada

${ }^{\mathrm{d}}$ Collaborative for Advanced Landscape Planning, Centre for Interactive Research \& Sustainability, University of British Columbia, 2321 - 2260 West Mall, Vancouver, BC, V6T1Z4, Canada

${ }^{1}$ Contact author \& Author present address:

Dep. Ciencias del Medio Natural, Universidad Pública de Navarra

Campus de Arrosadia, Pamplona, Navarra, 31006, Spain

Tel: +34 948 169859; Fax: +34 948 168930; E-mail: juan.blanco@unavarra.es

\section{ACKNOWLEDGEMENTS}

The authors are sincerely thankful to the help and support provided by the three pilot communities at every stage of the project. We also want to thank Alex Adams for his efforts during the early stages of the project that contributed to the takeoff of the ideas introduced here. Last but not least, we thank the Pacific Institute for Climate Solutions (PICS) for their financial support through the Carbon Management in BC Call for Applied Research. The activities reported here have been funded through the project "Community Fire Interface Biomass Utilization For Heating Fuel".

This work was presented at the "North America Forest Soils Conference, Montana 2013", in the "New Technologies in Soil Research" session. 


\title{
Soil Organic Matter: a sustainability indicator for wildfire control and bioenergy production in the urban/forest interface
}

\begin{abstract}
Many rural communities in British Columbia (western Canada) are increasingly at risk from wildfire as temperatures rise and droughts become more frequent. In addition, these communities are also faced with rising fuel costs, and a growing demand for heat as their populations increase. The fact these communities are surrounded by forests presents an opportunity to combine community wildfire risk abatement with bioenergy development. Here we show how the ecological model FORECAST was linked with GIS and economic models to create a freely available on-line tool (FIRST Heat) to help other communities make their own screening-level ecological assessments of combining wildfire risk control with district heating systems. The tool incorporates an ecological sustainability index based on the relative change in soil organic matter (SOM) after 50 years of management compared to initial levels. Two thresholds were defined: 10\% SOM lost as "warning" level, and 20\% SOM lost as "critical" level. The tool was able to adequately capture the influences of ecological zone, stand age, site quality, and intensity of forest management on SOM losses. Stands in the sub-boreal and arid interior were significantly more exposed to SOM losses than in other ecological zones, as well as soils in old-growth forests. Stands in poor sites were significantly more sensitive to forest management than young and fertile sites. All things considered, our results show the suitability of incorporating ecological models and SOM thresholds in user-friendly decision-support tools to successfully transfer scientific knowledge on forest soils to local stakeholders and decision makers.
\end{abstract}

Keywords: forest biomass, ecological model, sustainable energy, green economy, sustainable forest management, climate change mitigation, FIRST Heat.

Abbreviations: FIRST Heat: Fire Interface Rural Screening Tool for Heating, SOM: Soil Organic Matter, BEC: Biogeoecological zone of B.C., SBS: Sub-Boreal Spruce ecological zone, ESSF: Engelmann Spruce - Subalpine Fir ecological zone, ICH: Interior Cedar-Hemlock ecological zone, IDF: Interior Douglas-fir ecological zone, MS: Montane Spruce ecological zone. 


\section{INTRODUCTION}

Since Canada's census of 1981, there has been a clear trend for rural suburban spaces to grow in population at a rate higher than city centers (Hirsch and Funglem, 2006). In British Columbia (BC, western Canada) the area of the forest-urban interface has been steadily increasing over the last few years, becoming vulnerable to damage and evacuation orders as wildfires strike. All forests in interior $\mathrm{BC}$ are naturally adapted to fire as an ecological disturbance with a specific fire regime: a combination of fire frequency, intensity, and severity (Johnson et al., 2001). However, external factors are changing natural fire regimes. For example, excessive fire suppression, or increased tree mortality by pest attacks cause an accumulation of fuel and therefore increases fire occurrence and/or intensity (Keeley et al., 1999; Jolly et al., 2012). Fire frequency has also increased from direct anthropogenic sources (escaped fires, sparks, etc.) that occur when more people live in the urban-forest interface. Direct links between climate change and more fires have also been reported (Westerling et al., 2006), and an increase in fire frequency is predicted for western North America (Hirsch and Fuglem, 2006; Nitschke and Innes, 2013).

Due to this increasing area under wildfire risk, communities around $\mathrm{BC}$ are implementing preventive forest management to reduce wildfire risk. These activities are generating woody debris from stand density reduction. Until now, this biomass was removed from site and then burned in piles, so it would not fuel future wildfires. However, rural communities now incur fuel prices more expensive than in cities because fossil fuels have to be transported from the main population centers. Therefore, there are economic as well as environmental reasons to increase the use of woody debris as a source of energy generated from the management of the forest-urban interface.

The ecological context of the biomass residue is an important consideration, however, because removing harvesting residues could have negative impacts on fauna (Sullivan et al., 2011) and flora (Blanco, 2012). Long-term nutrient losses have been described as important for altering ecosystem productivity (Blanco et al. 2005, 2012; Wang et al. 2013). Maintaining ecosystem productivity is fundamental to the principles of sustainable forest management. However, there is still no effective method for measuring and monitoring the impacts of management activities on ecosystem productivity 
(Fox, 2000). Forest productivity, like soil or site quality, is a value-based concept related to the objectives of ecosystem management, and hence will be management and ecosystem-dependent (Schoenholtz et al., 2000).

Total soil organic matter (SOM) has been linked to ecosystem productivity, being recommended for monitoring programs (Peng et al. 2002, Seely et al. 2010). SOM carbon is commonly recognized as one of the key parameters of soil quality, yet quantitative assessments of its contribution to soil quality are often lacking. Through its role in aggregate stability SOM influences soil porosity, and thus gas exchange reactions and water relationships. SOM is also a critical pool in the carbon cycle and a repository of nutrients, and through its influence on many fundamental biological and chemical processes it plays a pivotal role in nutrient release and availability (Henderson, 1995; Nambiar, 1997). The importance of SOM as a structural and functional component of soil productive capacity and in providing the critical linkage between management and productivity is widely recognized for forest soils (Henderson, 1995; Nambiar, 1997).

Sustainable forest management requires maintenance of the soil resource including its biological, chemical and physical properties and processes. Of highest priority, is to quantify the practical consequences of changes in soil organic matter that are important for sustainable forestry. Defining qualitative criteria for SOM is further hampered by the fact that the same carbon content in soil translates into different soil productive capacity (Schoenholtz et al., 2000), depending on soil types, climatic regions, land-use, and species composition (Doran and Parkin, 1994).

If the anticipated economic rotation for a particular site is shorter than the associated ecological rotation, a decline in ecosystem productivity will result (Kimmins et al. 2010). However, because of the buffering capacity provided by the nutrient capital stored within SOM, the decline may be subtle and not easily detected after a single rotation. Evidence from ecosystems subject to long-term harvesting (plantations in the southern US [Fox, 2000], New Zealand [Sims et al., 1988], Australia [Johnson, 1992], China [Bi et al., 2007], Spain [Blanco et al., 2005], and South Africa [Evans, 1996]) 
supports this contention but also indicates that the decline in productivity will be cumulative and increase non-linearly across multiple rotations.

Therefore, the challenge for planners and local managers in rural BC is how to keep their communities safe, while reducing energy costs by using forest biomass produced from sustainable forest management. Together, these issues make for a complex picture as communities struggle to realize the potential of their forest-urban interface areas. A joint project involving the University of British Columbia, Community Energy Association and Wood Waste to Rural Heat Project has developed a tool called FIRST Heat. The tool uses SOM as an indicator of long-term ecological impacts, and provides a "traffic light" index to help forest managers and community planners to identify the situations in which biomass removal could produce undesirable long-term ecological consequences. In designing this tool, we have tried to address four of the 10 principles recently identified by Mea and Smith (2012) as basic to manage nutrient cycling in forest biomass production for energy (risk mapping, developing site-specific nutritional management plans, considering off-site impacts, and using decision-making aids). The objective of this paper is to analyze the sensitivity of the FIRST Heat tool to project SOM changes in different forest types, and its capacity to account for differences among ecological zones, site qualities, and forest ages.

\section{MATERIALS AND METHODS}

The calculator "Fire Interface Rural Screening Tool for Heating" (FIRST Heat) is a Microsoft Excel® spreadsheet in which users can select different options from drop-down menus and input parameter values specific to their communities (or select among the default values). The tool is freely available at the Community Energy Association website (http://www.communityenergy.bc.ca/resourcesintroduction/first-heat). FIRST Heat combines estimation of future tree growth from an ecological model, engineering calculations describing district heating systems, and economic features estimating the associated financial costs and benefits. The tool's interface, and its energy, financial, and engineering aspects are described in Blanco et al. (2013), whereas the tree biomass modelling is described in depth in Kimmins et al. (1999, 2010), and soil processes modeling are briefly described below. 


\subsection{Study areas}

Three pilot communities were selected based on their small population size, no existing district energy systems, and location. The latter translates into difficult access to the natural gas grid, surrounded by forests prone to wildfires, and representing different biogeoclimatic (BEC) zones (Pojar et al., 1987) to provide a diversity of forest types in the study (Figure 1). These communities are:

Burns Lake (Northern BC), in the interior plateau with its surrounding forests mostly within the SubBoreal Spruce biogeoclimatic zone (SBS). In contrast to boreal, sub-boreal climate is slightly less continental, thus slightly warmer in January and cooler in July. Sub-boreal winters are shorter and the vegetative season slightly longer. Mean annual temperature of the SBS ranges from 1.7 to $5^{\circ} \mathrm{C}$. Average temperature is below $0^{\circ} \mathrm{C}$ for $4-5$ months of the year, and above $10^{\circ} \mathrm{C}$ for $2-5$ months. Mean annual precipitation data from long-term stations ranges from 440 - $900 \mathrm{~mm}$, of which $25-50 \%$ is snow. Mean annual precipitation can range from 415 to $1650 \mathrm{~mm}$ (Meidinger and Pojar 1991). Upland soils are primarily from the Luvisolic, Podzolic, and Brunisolic soil orders (Boralfs, Udalfs, Spodosols, and Inceptisols in U.S. Soil Taxonomy, SCWG 1998), being the most common soils found on the abundant morainal deposits. Imperfectly to poorly drained sites in the SBS typically have Gleysols or gleyed subgroups of Luvisols, Podzols, or Brunisols. These conditions create a landscape where hybrid Engelmann-white spruce (Picea engelmannii x glauca) and subalpine fir (Abies lasiocarpa) are the dominant trees. Extensive stands of lodgepole pine (Pinus contorta) occur in the dryer portions of the zone due to numerous past fires. Wetlands are abundant, dotting the landscape in poorly drained areas. Secondarily in importance in the area is the Engelmann Spruce - Subalpine Fir (ESSF) zone. ESSF's climate is characterized by a long cold winter and a short cool summer, and only trees that survive long periods of frozen ground occur. Engelmann spruce and sub-alpine fir dominate wetter areas, with lodgepole pine as a pioneer after disturbance and mountain hemlock in higher snowfall areas.

Sicamous (Shuswap Valley), mainly in the Interior Cedar-Hemlock biogeoclimatic zone (ICH). Continental climate (cold winters, warm and dry summers) defines the area. The mean annual precipitation is $500-1200 \mathrm{~mm}$ of which $25-50 \%$ falls as snow and the mean annual temperature is 2 - 
8. $7^{\circ} \mathrm{C}$ (Meidinger and Pojar, 1991). Soils are typically Podzols and Brunisols with Mor humus forms (Spodosols, and Inceptisols in U.S. Soil Taxonomy). Podzolic soil development occurs in the wetter regions whereas Brunisolic (Inceptisol) soil development is more common in the very dry to moist regions. Due to steep topography, extensive wetlands are uncommon. Where wetlands occur, gleysols and organic soil development can occur (Aqu-suborders in the U.S. Soil Taxonomy). Western hemlock (Tsuga heterophylla) and western redcedar (Thuja plicata) are characteristic species but spruce (Engelmann-white hybrids), and subalpine fir are not unusual. Douglas-fir (Pseudotsuga menziesii) and lodgepole pine are generally found on drier sites. Secondary in importance and located in the valley bottoms is the Interior Douglas fir (IDF) zone, with warmer and drier summers. Douglasfir is the dominant tree species, occurring in open savannah-like stands on drier sites. Wetter sites at higher elevations support dense stands of Douglas-fir. Common pioneer tree species after disturbance are lodgepole pine at upper elevations and ponderosa pine (Pinus ponderosa) at lower elevations. At higher elevations there are some stands belonging to the ESSF zone.

Invermere (Kootenay mountains), mostly in the Montane Spruce biogeoclimatic zone (MS). The MS is typified by short, warm summers and long cold winters. Annual precipitation is between $380-900$ $\mathrm{mm}$ and the mean annual temperature is between $0.5-4.7^{\circ} \mathrm{C}$ (Meidinger and Pojar, 1991). Soils are typically Brunisols or Luvisols (Inceptisols and Boralfs/Udalfs in the U.S. Soil Taxonomy). In the wetter regions, podzolic soil development may occur. Engelmann and hybrid spruce, and varying amounts of subalpine fir as characteristic tree species. However, due to past wildfires successional forests of lodgepole pine, Douglas-fir and trembling aspen (Populus tremuloides) are common. In the valley bottoms there are stands in the IDF zone, whereas in the higher areas of the surrounding mountains there is some occurrence of stands belonging to the MS and ESSF zones.

Personal interviews and a review of official documents were carried out on-site in each community to gather information on local wildfire protection plans, management recommendations, ecological surveys, and other related information. For each zone, GIS maps of the surrounding area in a $25-\mathrm{km}$ radius were generated, using data from BC's Vegetation Resources Inventory (available at: http://www.for.gov.bc.ca/hts/vri/). Forest stands (GIS polygons) in each map were classified into 
different forest types depending on their biogeoclimatic zone, dominant tree species, density and tree age (see list of stand types in Table S1 in the Supplementary material). Each forest type was individually simulated the ecosystem model FORECAST (Kimmins et al., 1999) (see below).

\subsection{Forest biomass modeling}

\subsubsection{Wildfire risk management scenarios}

The information provided by the communities, combined with FireSmart guidelines (Partners in Protection, 2003) was used to design three different management regimes. They represent the tradeoffs faced by many communities between carrying intensive but costly forestry operations to maintain wildfire risk at minimum, and the cost of such operations. In all management regimes, broadleaf trees were left on site without thinning or harvesting, to maintain their effect as wildfire barriers (Partners in Protection, 2003).

Intense management to keep wildfire risk at minimum: post-thinning conifer target density was 121 trees ha ${ }^{-1}$ ( 6 meters between crowns) in Burns Lake and Sicamous, 65 trees ha ${ }^{-1}$ (11 meters between crowns) in Invermere, branches pruned up to $3 \mathrm{~m}$, undergrowth control operations carried out every 5 years, removing all new trees, understory and coarse woody debris with diameter $>10 \mathrm{~cm}$.

Moderate management: post-thinning target conifer density of 121 trees $^{-1} \mathrm{a}^{-1}(6$ meters between crowns), branches pruned up to $3 \mathrm{~m}$, undergrowth control operations every 10 years, removing all new trees and understory, and coarse woody debris with diameter $>10 \mathrm{~cm}$.

Minimum management to keep wildfire risk inside safety standards: post-thinning conifer target density of 286 trees $^{-1} \mathrm{p}^{-1}$ ( 3 meters between crowns), branches pruned up to $2.5 \mathrm{~m}$, undergrowth control operations every 10 years, removing all new trees and understory, and coarse woody debris with diameter $>10 \mathrm{~cm}$.

\subsubsection{The ecological forest model FORECAST}

Tree and understory growth was simulated with the ecosystem-level forest model FORECAST 
(Kimmins et al., 1999). FORECAST is a management-oriented, deterministic, stand-level forest growth and ecosystem dynamics simulator that operates at annual time steps. A detailed description is provided in previous publications (Kimmins et al., 1999, 2010), and therefore only a summary is provided here. The model uses a mass balance approach to estimate how nutrients circulate in a forest ecosystem, and how their availability limits tree growth together with available light in the canopy (Figure 2).

Model calibration: For each forest type, calibration data are assembled that describe the accumulation of biomass (above and below-ground components) in trees and minor vegetation for three chronosequences of stands, each one developed on homogeneous conditions, representing three different nutritional qualities. Tree biomass and stand self-thinning rate data are often generated from height, DBH and stand density output of traditional growth and yield models in conjunction with species-specific component biomass allometric equations. To calibrate the nutritional aspects of the model, data describing the concentration of nutrients in the various biomass components are required. FORECAST also requires data on the degree of shading produced by different quantities of foliage and the photosynthetic response of foliage to different light levels. A comparable but simpler set of data for minor vegetation must be provided if the user wishes to represent this ecosystem component. Lastly, data describing the rates of decomposition of various litter types and soil organic matter are required for the model to simulate nutrient cycling. The model is data-intensive, but most of the data can be found in regular forest inventories carried out by companies or forest services (tree size, age, mortality), and through simple chemical analysis (nutrient contents in plants and soil). Some more specific parameters such as decomposition or photosynthetic rates may need site-specific studies unless published studies of the target species in the ecological regions of interest are available.

The FORECAST datasets used for this project were based on existing calibration datasets assembled as part of a previous research (Seely et al., 2010). In all cases calibration data (biomass accumulation rates, top height, diameter at breast height, and stand density) were derived from regional growth and yield tables in combination with species-specific allometric biomass equations. Other calibration data were derived from literature sources: nitrogen concentrations in biomass components (Kimmins et al., 
1979; Peterson and Peterson, 1992; Wang et al., 1996), decomposition rates (Prescott et al., 2000a, 2000b; Camiré et al., 2002), litterfall rates (Kimmins et al., 1979; Peterson, 1988; Li et al., 2003), light transmission (Messier et al., 1998; Leifers et al., 2002; Comeau and Heineman, 2003), light-limited growth rates (Mailly and Kimmins, 1997; Leifers et al., 2002; Claveau et al., 2002). Calibration values for the most important parameters can be found in those studies are not repeated here.

Model initialization. The detailed representation of many different litter types and soil organic matter conditions makes it impractical to measure initial litter and soil conditions directly in the field; consequently, the model is used to generate starting conditions, simulating the historical fire regimes until the system reaches a steady-state condition (for a broader discussion on this topic see, for example, Seely et al., 2002; Welham et al., 2002). Based on data on fire regimes for each BEC, the initial conditions were created for each ecosystem type using the parameters shown in Table S2 (Supplementary material).

Simulation of tree growth. Projection of stand growth and ecosystem dynamics is based upon a representation of the rates of key ecological processes regulating the availability of, and competition for, light and nutrient resources. The rates of these processes are calculated from a combination of historical bioassay data (biomass accumulation in component pools, stand density, etc.) and measures of certain ecosystem variables (e.g. decomposition rates, photosynthetic saturation curves, etc.) by relating biologically active components (foliage and small roots) with calculations of nutrient uptake, capture of light, and net primary production. With the calibration data obtained from different sources the model calculates the annual rates of different ecological processes (tree growth, litterfall production, mortality, etc.) based on the historical data on tree growth and density provided by the user. Change in biomass in each time step is derived from a series of age-biomass curves created with empirical data. Litterfall is calculated using user-defined values based on empirical litterfall rates. Mortality is derived from a series of age-stand density curves created with empirical data (for a detailed description on mortality simulation in FORECAST, see Kimmins et al., 1999). Mortality is calibrated through two different parameters: curves of historical stand density for different ages and the proportion of mortality that is due to non-interspecific competition factors. Together, both 
parameters allow simulating the endemic, low level mortality events caused by pests and diseases.

To estimate photosynthesis, FORECAST simulates canopy foliage biomass as a "blanket" that covers the stand and that is divided in several layers of $0.25 \mathrm{~m}$ height, each of them increasingly darker from the top to the bottom of the canopy. To calculate the nutritional aspects of tree and plant growth, FORECAST requires data on nutrient concentration in each different tree organ. Nutrient dynamics in this study were restricted to nitrogen, the most limiting nutrient in temperate and boreal forests (Seely et al. 2010). Effects of soil moisture limitation were assumed to be implicitly simulated by calibrating the model for different site qualities that are limited by water and nutrient availability, and by setting a maximum foliar area for each site quality (Kimmins 1993). However, this approach may be limited in the most arid sites, where an explicitly simulation of water limitation may be necessary (Kimmins et al. 2010). Data describing decomposition rates for various litter and humus types are required to simulate nutrient cycling. Decomposition rates are defined by the user (using values from empirical studies) and are affected by site quality, which in turn is defined depending on nutrient and water availability. Snags and logs are tracked by placing them into different biomass pool categories depending on their original sizes (with slower decomposition rates for snags and for stems with larger sizes).

Nitrogen cycling in FORECAST is based on a mass balance approach where $\mathrm{N}$ can exist in three distinct pools: 1) the plant biomass pool; 2) the available soil nutrient pool, and 3) the soil organic matter/forest floor pool. Inputs and outputs of $\mathrm{N}$ to the ecosystem are simulated in a four-stage process for each annual time step. Available nitrogen pool is calculated by simulating consecutively the different inputs and outputs of the biogeochemical cycle: deposition, fertilization, seepage, leaching, mineralization, immobilization (Figure 3). A detailed description of the simulation of each of these fluxes in FORECAST can be found in Blanco et al. (2012).

Scenario analysis. Three different forest age scenarios were simulated for each forest type: young forest (average stand age younger than 80 years), mature forest (average stand age between $80-150$ years), and old-growth (average stand age older than 150 years). For each forest type, management 
operations were simulated to start at the average stand age for each age scenario and lasted for 50 years. The resulting 50-year trends of tree, understory, and forest soil biomasses for each simulation were linked to each polygon type in the GIS map (see Blanco et al. [2013] for a detailed description of the biomass production estimations) In addition, for each stand type the percentage losses of total SOM after 50 years were calculated. To simplify the output information for FIRST Heat users, an "Ecological Sustainability Index" was created. This index indicates the proportion of stand types under wildfire abatement risk management that may have significant SOM losses. The index can have one of the following values: 1) Low ("green light"), most of the stand types will have no appreciable reductions in SOM after 50 years; 2) Moderate ("yellow light"), more than $40 \%$ of stand types will lose $10 \%$ or more of their initial total SOM after 50 years; and 3) Investigate ("red light"), some forest types may be heavily affected by forest management. For the last situation, more than $40 \%$ of stand types will lose $20 \%$ or more of the original SOM after 50 years, and detailed stand-specific ecological assessments are recommended.

Although for many interior BC communities, the mountain pine beetle epidemic is a catalyst for considering biomass heating projects and although infested wood can be used in these systems, the epidemics is already declining (Chen 2013) and the extraordinary salvage logging levels will likely last for only a few more years (Burton 2010). As the FIRST Heat Tool is a long term (50 years) planning tool that extends past these short-term pulse of biomass, much shorter than the forest growth simulations with FORECAST, we did not account for mountain pine beetle dynamics and its influence on wood supply, although background mortality levels induced by pests or other factors were included in the simulation. Finally, because the model has been evaluated before for an examination of soil productivity in BC forests (e.g. Seely, 2005; Seely et al., 2010; Blanco, 2012; among others), we did not carry again validation tests.

\subsection{Statistical analysis}

An initial one-way ANOVA was used to analyze differences among management intensities (factor) in relative changes in SOM after 50 years. Then, one-way ANOVAs (with the data split by management 
intensity) were used to test significant differences among the levels of each of the four factors that defined forest sites: management type, ecological (BEC) zone, site quality, and age class (each factor tested separately). Data were logit-transformed prior to analyses to achieve normality distribution for percentage values. Tukey's H.S.D. were used to detect significant differences between groups for each factor. Decision-tree analysis was used to study the capability of the FORECAST model to distinguish between different situations, and compared to the ad hoc threshold of 10\% losses of original SOM. Partitioning results were cross-validated using a k-fold cross-validation procedure $(\mathrm{k}=10)$. This method divides the original data into $k$ subsets. In turn, each of the $k$ sets is used to validate the model fit on the rest of the data, fitting a total of $k$ models. The model giving the best validation statistic is chosen as the final model. All statistical analyses were carried out using JMP v.5.0.1 (SAS Institute, NC, USA).

\section{RESULTS}

The model was able to simulate the evolution over time of SOM in a large variety of stand types (952 in total). Managing the urban-forest interface caused significant SOM losses compared to the nomanagement situation in all kinds of forest stands (Table 1). Intense management caused significantly higher SOM losses than moderate and minimum management in all stand types except in medium and rich sites, where there was no differences among management intensities (Table 1). For a given ecological zone, stand productivity (determined by site quality and forest age) had clear influence on the resilience of the ecosystem to changes in soil organic matter (Figure 4).

In the more productive stands (medium site quality and young stand age), the influence of any type of management was small, and the temporal pattern of SOM was very similar to the non-managed stands: and initial slight increase as the young stand accumulated litter, followed by a slight drop as the forest soil stabilized. By the end of the 50 years, every management type caused no more than an additional $3 \%$ SOM losses compared to the non-management scenario, and an average of $\sim 8 \%$ losses of initial SOM. However, in less productive stands (poor site quality, mature stands) both non-management and minimum management allowed for a small build-up of SOM of $6.2 \%$ and $2.7 \%$, respectively, whereas 
the moderate and intense management, which removed twice as much trees from the stands as the minimum management, produced a drop in SOM since the beginning of the simulation, amounting to $10.7 \%$ and $11.3 \%$ losses in the moderate and intense management.

When SOM changes were summarized for all the ecological zones, it could be seen how SBS was more sensitive to SOM losses in all type of scenarios, with SOM losses that could reach $23.1 \%$ in 50 years under intense management (Figure 5). IDF was the second most sensitive ecological zone to SOM losses. It is also noticeable how stands in the two most extreme zones (SBS and IDF, boreal and semi-arid respectively) were prone to accumulate SOM if no wildfire risk prevention measures were taken. When estimates of SOM losses were grouped by stand age, there was a consistent trend to increase losses when increasing stand age, but the differences among age classes only became significant between young and old-growth stands when moderate wildfire prevention was applied (Figure 6). On average, all age classes also showed a tendency for small build-ups of SOM after 50 years when no management was used, but this trend was significantly weaker in the old-growth forests compared to the other two age classes (Figure 6). Poor sites were more sensitive than medium and rich sites, although these differences became significant only in the moderate and intensive wildfire risk management (Figure 7). On average, poor sites lost $11.8 \%$ of their initial SOM levels after 50 years if intensive management was applied. On the other hand, poor sites were also significantly more prone to accumulate SOM under no-management conditions, whereas the medium and rich sites kept virtually stable amounts of SOM.

The significant differences among groups for the four stand-defining variables allowed for a partitioning study in which a decision tree was used to separate situations with significant differences in SOM losses in a hierarchical way. Obviously, the first partition separated non-managed stands for those under management (Figure 8). After management, the second most important variable was the ecological zone, first separating the sub-boreal spruce (SBS) zone from the rest. Under all scenarios, SOM losses in SBS stands were above the $10 \%$ threshold. On the other hand, no scenarios in the ESSF, MS and ICH ecological zones produced SOM loses above $10 \%$ of the initial levels after 50 years, but in IDF the losses surpassed the $10 \%$ threshold depending first on the type of management 
and second on the stand age. Moderate management scenarios did not cause losses above $10 \%$ of initial SOM, but for the other management types, all stands with age $>80$ years lost more than $10 \%$ initial SOM. Splitting the young stands further, minimum management did not cause losses above the threshold, but with intense management there were average losses of $12.03 \%$ in medium sites (Figure 8). The decision tree had $\mathrm{r}^{2}=0.633$, and it showed a partition with values for cross validation ( $\mathrm{k}$-fold $=$ 10) of crossvalSSE $=28978.89$, which was the average of error the 10 folded cross-validations. This error was very similar to the error of the full sample SSE 28547.97, indicating the robustness and acceptable capacity of the model to predict and split correctly future samples.

\section{DISCUSSION}

Although there is wide consensus among the scientific community on the utility of ecological models (Messier et al. 2003), it has been more difficult to generate tools scientifically sound but practical for managers (although some examples already exist, see Kimmins et al 2010). In this work we present a novel approach: linking an ecological model, a GIS database, and a user-friendly spreadsheet to create a communication tool easily used by managers. FIRST Heat represents a proof of concept, and we do not pretend our simulations to be an accurate representation of specific stands or forests. Rather, we intended to test the ecological engine of the tool (the FORECAST model) capability to differentiate among different stand types, environmental conditions, and management regimes.

Partners in Protection's (2003) guidelines for wildfire safety in the urban-forest interface define an initial intense operation to reduce conifer stand density, followed by a continuous maintenance management. To avoid problems of excessive windthrow losses among the remaining trees following a sudden reduction of stand density, thinning operations were designed in two steps where $50 \%$ of harvestable trees were removed per step, and each step separated by 10 years. As a consequence, during the first 10 years of management a large amount of biomass was generated (Blanco et al. 2013). Although our previous research has showed that implementing different levels of stand density control may not produce large differences in biomass production during the regrowth period (Blanco et al. 2013), this biomass production could have important ecological consequences. 


\subsection{Capability of FIRST Heat to discriminate among factors influencing SOM losses}

The moderately high $\mathrm{r}^{2}$ of the regression tree indicated an acceptable result of the decision tree when splitting the different samples into groups. The cross-validation procedure also indicated the capability of the selected tree to predict acceptably future samples into the correct categories with an estimated error similar to the one in the set of simulations. In the intermediate and intense management scenarios, long-term biomass production was predicted to decline because biomass removal depleted nutrients from the sites thereby reducing site quality and tree productivity. This phenomenon was more pronounced in areas with slower growth rates: the sub-boreal stands in the SBS zone, and the semi-arid stands in the IDF zone. However, even the most productive sites such as those in Sicamous could be affected. Interestingly, our projections showed that in absence of management, both areas would tend to accumulate SOM.

The reason for this higher sensitivity to management is probably caused by the relatively lower SOM in IDF and SBS than in the other three ecological zones (ESSF, MS, and ICH). These relatively low levels of SOM are likely related to frequent and intense stand replacing fires over the past several hundred years in pine forests (Wong et al., 2004). Natural disturbances and stand history have a significant and persistent effect on SOM (Robertson et al., 1997). Such fires commonly result in the consumption of significant quantities of biomass and litter (thus reducing future sources of soil organic matter) and an associated loss of soil nutrients via volatilization and leaching (Boerner, 1982; González-Pérez et al., 2004; Johnson et al., 2007). The model seems to adequately capture the importance of the ecological zone (and therefore stand composition) as the main factor causing differences among sites in SOM losses under management for wildfire control.

Moreover, the generally low levels of soil productivity in the two ecological zones most sensitive to SOM loses (the sub-boreal SBS and the arid IDF, with mean site index values for these sites are $<16$ ) is partly a reflection of low soil nitrogen levels. The relationship between forest productivity and $\mathrm{N}$ availability has been described several times in forest soils (Ågren, 1985; Reich et al., 1997; Perry, 1998; among others). The relationship is based on the fact that SOM is an important source of 
nutrients that can be released at relatively constant levels over long periods of time. SOM also improves soil structure and water holding capacity. Others have also found SOM to be a good indicator of site productivity for similar reasons (Doran and Parkin, 1994; Prescott et al., 2000a, b: Seely et al. 2010).

Secondary to the ecological zone, stand age also showed up as a significant factor determining the effects of forest management on SOM. The simulations for many stands showed SOM following a pattern previously described for forest soils: first a small peak after harvesting, then decrease for about 15 years and then slow increase (Martin et al., 2002) (Fig. 4). In productive stands, the small peak about 15-20 years after stand initiation was a consequence of the humification of the massive input of woody debris left on site after the disturbance caused by management. Sharp declines in SOM after harvesting followed by recovery have been described in chronosequence studies (Federer, 1984; Martin et al., 2002). However, although the model showed considerable fluctuation of litter mass pools following the initial thinning in most stands (data not shown), in the short-term soil carbon was largely unaffected by management activities in most of the simulated scenarios, except the most sensitive ones. Hence the decision tree showed how with a threshold of $10 \%$ reduction after 50 years, the FIRST Heat tool was able to discriminate 191 out of 952 scenarios (20.1\%) as potentially problematic from an ecological sustainability point of view. These results indicate the capability of the decision-support tool to match the observed scarce effect of forest management on total SOM at half-century time scales (Johnson and Curtis 2001). However, the tool was sensitive enough to simulate how the longterm effect of management activities on soil carbon is dependent, at least in part, on the time the forest has had to accumulate soil organic matter.

For example, after stand-replacing fires, forest stands usually have relatively low amounts of SOM and often show a gradual increase in SOM as the forests develop (Johnson, 1992; Huntington, 1995; Blanco 2012). Old-growth forests, in contrast, typically contain significant quantities of SOM. These forests are more susceptible to losses in organic carbon following harvest and conversion to managed stands (Harmon et al., 1990; Johnson, 1992; Schulze et al. 2000). In addition, old-growth forests usually had lower productivities compared to young or mature stands, which translate in lower litter 
production rates. Litter pools represent a small fraction of the total ecosystem carbon, but rates of litter production can have a significant impact upon carbon stored in the SOM, as litter is the main SOM input in the forest soil (Alban, 1982: Seely et al. 2002), and the main source of mineralized N (Blanco et al. 2011). If there is less litter entering the forest soil, and also in more open stands where litter decomposition can be reduced compared to closed-canopy stands, nutrients could become increasingly limiting (Blanco et al. 2005). Limitation in nutrient availability produces lower tree growth, and therefore keeps the canopy more open, with levels of available light for the understory higher than in the non-managed forests. As a consequence, understory would grow more, competing more intensively with trees and therefore reinforcing nutrient limitation (Bi et al. 2007; Kimmins et al. 2008; Blanco 2012).

The latest factor to be discriminated by the decision tree was site quality (measured as site index or dominant tree height at a given age). However, most of the influence on resource availability is already accounted for in the previous two factors in the decision tree (ecological zone and forest age). The contribution of soil to site index is also the result of interactions with other site factors, tree breeding, and silvicultural practices that manipulate soil function (Schoenholtz et al., 2000). However, from our results it seems clear that poor sites should be more carefully managed in order to avoid overexploiting their productive capacity, as they will need longer times to recover from human activities (Blanco, 2012). Site quality, however, is not a fixed stand attribute, and forest management can improve or reduce it (Kimmins et al., 2008). Modelling, combined with risk mapping, could be important tools to design site-specific management plans for biomass production that could avoid nutrient losses from the stands in the long term (Mea and Smith 2012). It is becoming clear that modeling forest ecosystems under changing conditions (e.g., new management practices, forest decline, climate change, invasive species, etc.) has to be done with models able to simulate changes in site quality and traditional statistical growth and yield models are unlikely of fulfill these requirements (DeAngelis and Mooij, 2003; Bi et al., 2007: Seely et al. 2010; Kimmins et al. 2010). 


\subsection{The use of models to estimate potential changes in SOM}

Detecting changes in soil $\mathrm{C}$ brought about by changes in land management requires precise field measurements, and a number of soil characteristics make this challenging (Conant et al., 2003). Having reliable monitoring techniques, and more importantly tracking the consequences of soil disturbance for forest growth and hydrology are paramount to improving understanding and prediction of the practical consequences of forest practices (Curran et al., 2005).The modelling results presented here are similar to results from previous studies in British Columbia (Seely et al., 2002, 2010; Blanco, 2012), providing support for the use of total site SOM (in particular relative losses of SOM on a given site) as an effective measure of the maintenance of long-term ecosystem productivity. Seely et al. (2010) indicated that monitoring plans of forest management sustainability should at least be able to detect losses of $20 \%$ SOM, at monitoring intervals of 10 years. Also, $20 \%$ has been determined as a key threshold for loss of ecosystem productivity (DiStefano, 2001; Yanai et al, 2003).

Given the inherent uncertainties associated with a modelling exercise of the characteristics presented here, we think that using a threshold of $10 \%$ SOM losses in 50 years is an adequate level to "light on" the yellow light in our decision-support tool, advising for more accurate studies and still be in the safe side. In addition, in the most severe cases of potential SOM losses (most of the them in the sub-boreal SBS zone), the model predicted an average of $23 \%$ losses, in the "red light" zone that indicates additional ecological assessments are needed before implementing any forest management for biomass. Therefore, we consider that given the capability of the tool to segregate between different site conditions, risks for nutrient losses, and add off-site costs, FIRST Heat would be a valuable tool to follow the 10 principles of nutrient management in forest biomass production regimes (Mea and Smith 2012).

\section{CONCLUSIONS}

Our analysis has shown the feasibility of linking ecological science with financial, social, and energy models to ensure that ecological sustainability is incorporated into the decision process for local forest 
management plans in rural communities. It is possible to satisfy multi-objective management goals by linking a reduction in wildfire risk and energy production in an ecologically sustainable way, provided the ecological conditions underlying forest productivity and health are understood. Therefore, the use of the "traffic light approach" provides a good example of the practical use of these thresholds of SOM change to define sustainable forest management plans that are easy to communicate to stakeholders and local decision makers. Although the primary variable to make decision would be wildfire safety for the communities, especially when managing the stands right besides human population and infrastructures, management practices must be carefully designed so as not remove more organic matter (e.g. slash, forest floor material, coarse woody debris) from the site than is necessary (Ballard, 2000; Prescott et al., 2000a). Having a preliminary assessment of the stand types more at risk of losing SOM under different management plans is indeed useful information on which base more informed decisions.

\section{REFERENCES}

Ågren, G.I. 1985. Theory for growth of plants derived from the nitrogen productivity concept. Physiol. Plant. 64:17-28.

Alban, D.H., 1982. Nutrient accumulation by aspen, spruce and pine. Soil Sci. Soc. Am. J. 46:853861.

Bi, J., J.A. Blanco, J.P. Kimmins, Y. Ding, B. Seely, and C. Welham. 2007. Yield decline in Chinese Fir plantations: A simulation investigation with implications for model complexity. Can. J. For. Res. 37:1615-1630.

Blanco, J.A. 2012. Forests may need centuries to recover their original productivity after continuous intensive management: an example from Douglas-fir. Sci. Tot. Environ. 437:91-103.

Blanco, J.A., J.B. Imbert, and F.J. Castillo. 2011. Thinning affects Pinus sylvestris needle decomposition rates and chemistry differently depending on site conditions. Biogeochem. 106:397-414.

Blanco J.A., X. Wei, H. Jiang, C.Y. Jie, and Z.H Xin. 2012. Enhanced nitrogen deposition in southeast China could partially offset negative effects of soil acidification on biomass production of Chinese fir plantations. Can. J. For. Res. 42:437-450. 
Blanco, J.A., M.A. Zavala, J.B. Imbert, and F.J. Castillo. 2005. Sustainability of forest management practices: Evaluation through a simulation model of nutrient cycling. For. Ecol. Manage. 213:209-228.

Boermer, R.E.J. 1982. Fire and nutrient cycling in temperate ecosystems. BioScien. 32:187-192.

Burton, P.J. 2010. Striving for Sustainability and Resilience in the Face of Unprecedented Change: The Case of the Mountain Pine Beetle Outbreak in British Columbia. Sustainability 2: 24032423.

Camiré, C., J.A. Trofymow, L. Duschene, T.R. Moore, L. Kozak, B. Titus, M. Kranabetter, C. Prescott, S. Visser, I. Morrison, M. Siltanen, S. Smith, J. Fyles, and R. Wein. 2002. Rates of litter decomposition over 6 years in Canadian forests: influence of litter quality and climate. Can. J. Forest Res. 32:789-804.

Chen, H. 2013. A spatiotemporal pattern analysis of historical mountain pine beetle outbreaks in British Columbia, Canada. Ecography 36: 001-013.

Claveau, Y., C. Messier, P.G. Comeau, and K.D. Coates. 2002. Growth and crown morphological responses of boreal conifer seedlings and saplings with contrasting shade tolerance to a gradient of light and height. Can. J. For. Res. 32:458-468.

Comeau, P.G., and J.L. Heineman. 2003. Predicting understory light microclimate from stand parameters in young paper birch (Betula papyrifera Marsh) stands. For. Ecol. Manage. 180:303315.

Conant, R.T.,G.R. Smitch, and K. Paustian. 2003. Variability of soil carbon in forested and cultivated sites: implications for change detection. J. Environ. Qual. 32:278-286.

Curran, M.P., R.E. Miller, S.W. Howes, D.G. Maynard, T.A. Terry, T. Heninger, R.L. Niemann, K. Van Rees, R.F. Powers, and S.H. Schoenholtz. 2005. Progress towards more uniform assessment and reporting of soil disturbance for operations, research, and sustainability protocols. Forest Ecol. Manage. 220:17-30.

DeAngelis, D.L., and W.M. Mooij. 2003. In praise of mechanistically rich models. In: C.D. Canham, J.J. Cole and W.K. Lauenroth (Eds.) Models in ecosystem science. Princeton University Press, Princeton, NY, $476 \mathrm{pp}$. 
Di Stefano, J. 2001. Power analysis and sustainable forest management. Forest Ecol. Manage. 154:141-153.

Doran, J.W., and T.B. Parkin. 1994. Defining and assessing soil quality. In: J.W. Doran, D.C. Coleman, D.F. Bezdick, and B.A. Stewart. (Eds.), Defining Soil Quality for a Sustainable Environment. Soil Science Society of America, Special Publication No. 35, pp. 3-21.

Evans, J. 1996. The sustainability of wood production from plantations: evidence over three successive rotations in the Usutu Forest, Swaziland. Commonwealth For. Rev. 75:234-239.

Federer CA. 1984. Organic matter and nitrogen content of the forest floor in even-aged northern hardwoods. Can. J. For. Res. 4:763-767.

Fox, T.R. 2000. Sustained productivity in intensively managed plantations. For. Ecol. Manage. 138:187-202.

González-Pérez, J.A., F.J. González-Vila, G. Almendros, and H. Knicker. 2004. The effect of fire on soil organic matter - a review. Env. Inter. 30:855-870.

Harmon, M.E.,W.K. Ferrel, and J.F. Franklin. 1990. Effects on carbon storage of conversion of oldgrowth to young forests. Science 247, 699-702.

Henderson, G.S. 1995. Soil organic matter: a link between forest management and productivity. In: W.W. McFee, and J.M. Kelly (Eds.) Proceedings of the 8th North American Forest Soils Conference on Carbon Forms and Functions in Forest Soils. Soil Sci. Soc. Ame. Madison, WI, pp. 419-435.

Hirsch, K.G., and P. Fuglem. (Eds.) 2006. Canadian wildland fire strategy: background syntheses, analyses, and perspectives. Canadian Council of Forest Ministers, Nat. Res. Canada, Can. For. Ser., Nort. For. Cen., Edmonton, AB.

Huntington, T.G., 1995. Carbon sequestration in an aggrading forest ecosystem in the southeastern USA. Soil Sci. Soc. Am. J. 59:1459-1467.

Johnson, D.W.1992. Effects of forest management on soil carbon storage. Water, Air Soil Poll. 64:83120.

Johnson, D.W., and P.S. Curtis. 2001. Effects of forest management on soil C and N storage: metaanalysis. For. Ecol. Manage. 140:227-238. 
Johnson, E.A., K. Miyanishi, and S.R.J. Bridge. 2001. Wildfire regime in the boreal forest and the idea of fires supresison and fuel builup.. Cons. Biol. 15:1554-1557.

Johnson, D., J.S. Murphy, R.F. Walker, D.W. Glass, W.M. Watkins, and W.W. Miller. 2007. Wildfire effects on forest carbon and nutrient budgets. Ecol. Eng. 31:183-192.

Jolly, W.M., R. Parsons, J.M. Varner, B.W. Butler, K.C. Ryan, and C.L. Gucker. 2012. O mountain pine beetle outbreaks change the probability of active crown fire in lodgepole pine forests? Comment. Ecology 93:941-946.

Keeley, J.E., C.J. Fotheringham, and M. Morais. 1999. Re-examining fire suppression Impacts of brushland fire regimes. Science 284:1829-1832.

Kimmins, J.P. 1993. Scientific foundations for the simulation of ecosystem function and management in FORCYTE-11. Forestry Canada, Northwest Region, Information Report NOR-X-328, Edmonton, $\mathrm{AB}, 102 \mathrm{pp}$.

Kimmins J.P., J.A. Blanco, B. Seely, C. Welham, and K. Scoullar. 2008. Complexity in Modeling Forest Ecosystems; How Much is Enough? For. Ecol. Manage. 256:1646-1658.

Kimmins, J.P., J.A. Blanco, B. Seely, C. Welham, and K. Scoullar. 2010. Forecasting Forest Futures: A Hybrid Modelling Approach to the Assessment of Sustainability of Forest Ecosystems and their Values. Earthscan Ltd. London, UK.

Kimmins, J.P, J.D. Catanzario, and D. Binkley. 1979. Tabular summary of data from the literature on the biogeochemistry of temperate forest ecosystems. ENFOR Project P-8. Natural Resources Canada. Vancouver, BC.

Kimmins, J.P., D. Mailly, and B. Seely. 1999. Modelling forest ecosystem net primary production: the hybrid simulation approach used in FORECAST. Ecol. Model. 122:195-224.

Kimmins, J.P., C. Welham, B. Seely, M. Meitner, R. Rempel and T. Sullivan, 2005. Science in forestry: why does it sometimes disappoint or even fail us? For. Chron. 81:723-734.

Leifers, V. J., B.D. Pinno, and K.J. Stadt. 2002. Light dynamics and free-to-grow standards in aspen dominated mixedwood forests. For. Chron. 78:137-145.

Li Z., W.A. Kurz, M.J. Apps, and S.J. Beukema. 2003. Belowground biomass dynamics in the Carbon Budget Model of the Canadian Forest Sector: recent improvements and implications for the estimation of NPP and NEP. Can. J. For. Res. 33:126-136. 
Mailly, D., and J.P. Kimmins. 1997. Growth of Pseudotsuga menziesii and Tsuga heterophylla seedlings along a light gradient: resource allocation and morphological acclimation. Can. J. Bot. 75:1424-1435.

Martin, W.L., R.L. Bradley, J.P. Kimmins. 2002. Post-Clearcutting Chronosequence in the B.C. coastal western hemlock zone: I. Changes in forest floor mass and N storage. J. Sustain. Forestry $14: 1-22$.

Mea, D., and C. Smith. 2012. Principles of nutrient management for sustainable forest bioenergy production. WIREs Energy Environ 2012, 1: 152-164 doi: 10.1002/wene.3.

Meidinger, D., and J. Pojar. 1991. Ecosystems of British Columbia. British Columbia Ministry of Forests. 330 pp. http://www.for.gov.bc.ca/hfd/pubs/Docs/Srs/SRseries.htm

Messier, C., S. Parent, and Y. Bergeron. 1998. Effects of Overstory vegetation on the understory light environment in mixed boreal forests. J. Veg. Sci. 9:511-520.

Messier, C., M.-J. Fortin, F. Schmiegelow, F.Doyon, S.G. Cumming, J.P. Kimmins, B. Seely, C. Welham, and J. Nelson. 2003. Modeling tools to assess the sustainability of forest management scenarios. In: P.J. Burton, C. Messier, D.W. Smith, and W.L. Adamowicz, (Eds.). Towards sustainable management of the boreal forest NRC Research Press, Ottawa, Canada.

Nambiar, E.K.S., 1997. Sustained productivity of forests as a continuing challenge to soil science. Soil Sci. Soc. Am. J. 60:1629-1642.

Nitschke, C.R. and Innes, J.L. 2013. Potential effect of climate change on observed fire regimes in the Cordilleran forests of South-Cnetral Interior, British Columbia. Climate Change 116:479-591. Partners in Protection, 2003. FireSmart: protecting your community from wildfire. Partners in Protection. Edmonton, AB.

Peng, C., J. Liu, Q. Dang, X. Zhou, and M. Apps. 2002. Developing carbon-based ecological indicators to monitor sustainability of Ontario's forests. Ecol. Ind. 1:235-246.

Perry, D.A. 1998. The scientific basis of forestry. Annu. Rev. Ecol. Sys. 29:435-466.

Peterson, E.B. 1988. An ecological primer on major boreal mixedwood species. In Management and utilization of northern mixedwoods. In: Samoil, J.K. (ed). Can. For. Serv. North. For. Cent. Inf. Rep. NOR-X-296. pp. 5-12. 
Peterson, E.B., and N.M. Peterson. 1992. Ecology, management, and use of aspen and balsam poplar in the prairie provinces. For. Can., Nort. For. Cen., Spec. Rep. 1., Edmonton, AB.

Prescott, C.E., L.L. Blevins, and C.L. Staley, C.L.. 2000a. Effects of clearcutting on decomposition rates of litter and forest floor in forests of British Columbia. Can. J. For. Res. 30:1751-1757.

Prescott, C.E., L.M. Zabek, C.L. Staley, and R. Kabzems, R. 2000b. Decomposition of broadleaf and needle litter in forests of British Columbia: influences of litter type, and litter mixtures. Can. J. For. Res. 30:1742-1750.

Pojar, J., K. Klinka, and D.V. Meidinger. 1987. Biogeoclimatic ecosystem classfication in British Columbia. For. Ecol. Manage. 22:119-154.

Reich, P.B., D.F. Grigal, J.D. Aber, and S.T. Gower. 1997. Nitrogen mineralization and productivity in 50 hardwoods and conifer stands on diverse soils. Ecology 78:335-347.

Robertson, G.P., K.M. Klingensmith, M.J. Klug, E.A. Paul, J.R. Crum, and B.G. Ellis. 1997. Soil resources, microbial activity, and primary production across an agricultural ecosystem. Ecol. Appl. 7:158-170.

Schoenholtz, S.H., H. Van Miegroet, and J.A. Burger. 2000. A review of chemical and physical properties as indicators of forest soil quality: challenges and opportunities. For. Ecol. Manage. 138:335-356.

Schulze, E.D., C. Wirth, H. Martin. 2000. Managing forests after Kyoto. Science 289:2058-2059.

Seely, B., 2005. Development of indicator 2-1 of the SFM Framework: Establishing thresholds, evaluating current practices, and refining monitoring strategies. Unpublished report prepared for Canadian Forest Products Ltd., Fort Nelson Division.

Seely, B., C. Welham, and J.P. Kimmins. 2002. Carbon Sequestration in a Boreal Forest Ecosystem: Results from the Ecosystem Simulation Model, FORECAST. For. Ecol. Manage. 169:123-135.

Seely, B., C. Welham, and J.A. Blanco. 2010. Towards the application of soil organic matter as an indicator of ecosystem productivity: Deriving thresholds, developing monitoring systems, and evaluating practices. Ecol. Ind. 10:999-1008.

Sims, A., G.R. Oliver, and W.J. Dyck. 1988. Effects of forest management on the long-term productivity of Nelson soils - Estimate of nutrient removal. Proj. Rec. No.2034, Forest Research.Institute, Rotorua, New Zealand. 
Soil Classification Working Group. 1998. The Canadian System of Soil Classification, 3rd ed.

Agriculture and Agri-Food Canada Publication 1646, 187 pp. Ottawa, ON. ISBN 0-660-17404-9.

Sullivan, T.P., D.S. Sullivan, P.M.F. Lingren, D.B. Ransome, J.G. Bull, and C. Ristea. 2011.

Bioenergy or biodiversity? Woody debris structures and maintenance of red-backed voles on clearcuts. Biom. Bioen. 35:4390-4398.

Wang W., X. Wei, W. Liao, J.A. Blanco, Y. Liu, S. Liu, G. Liu, X. Guo, and S. Guo. 2013. Evaluation of the effects of forest management strategies on carbon sequestration in evergreen broad-leaved (Phoebe bournei) plantation forests using FORECAST ecosystem model. For. Ecol. Manage. 300:21-32.

Wang, J. R., A.L. Zhong, S.W. Simard, J.P. Kimmins. 1996. Aboveground biomass and nutrient accumulation in an age sequence of paper birch (Betual papyrifera) in the Interior Cedar Hemlock zone, British Columbia. For. Ecol. Manage. 83:27-38.

Welham C., B. Seely, and H. Kimmins. 2002. The utility of the two-pass harvesting system: an analysis using the ecosystem simulation model FORECAST. Can. J. For. Res. 32:1071-1079.

Westerling, A.L., H.G. Hidalgo, D.R. Cayan, T.W. Swetnam. 2006. Warming and earlier spring increase western U.S. forest wildfire activity. Science 313:940-943.

Wong, C., H. Sandmann, and B. Donner. 2004. Historical variability of natural disturbances in British Columbia: A literature review. Forest Research Extension Partnership, Series 12, Kamloops, BC.

Yanai, R.D., S.V. Stehman, M.A. Arthur, C.E. Prescott, A.J. Freidland, T.G. Siccama, and D. Binkley 2003. Detecting change in forest floor carbon. Soil Sci. Soc. Am. J. 67:1583-1593. 
Table 1. Mean \pm standard error of the accumulated change in SOM ( $\%$ of initial value) after 50 years for different management regimes in different stand types. Negative values indicate net increases in SOM. Different letters in the same row stand for significant differences among management types with Tukey's H.S.D. For all the rows, the treatment effect was significant at $p<0.0001$. BEC: Biogeoclimatic zone in Pojar et al. (1987) site classification for British Columbia.

\begin{tabular}{lccrrrr}
\hline Stand type & F & $\mathbf{N}$ & \multicolumn{5}{c}{ Management regime } \\
& & & \multicolumn{1}{c}{ Intense } & \multicolumn{1}{c}{ Moderate } & \multicolumn{1}{c}{ Minimum } & No management \\
\hline BEC Zone & & & & & \\
SBS & 461.490 & 196 & $-25.03 \pm 0.62 \mathrm{a}$ & $-18.53 \pm 0.49 \mathrm{~b}$ & $-14.31 \pm 0.54 \mathrm{c}$ & $4.95 \pm 0.73 \mathrm{~d}$ \\
ESSF & 89.357 & 253 & $-4.66 \pm 0.58 \mathrm{a}$ & $-4.33 \pm 0.66 \mathrm{~b}$ & $-4.66 \pm 0.58 \mathrm{ab}$ & $7.33 \pm 0.62 \mathrm{c}$ \\
MS & 47.740 & 84 & $-5.04 \pm 0.59 \mathrm{ab}$ & $-4.39 \pm 0.55 \mathrm{~b}$ & $-6.65 \pm 0.35 \mathrm{a}$ & $10.70 \pm 0.44 \mathrm{c}$ \\
ICH & 43.492 & 307 & $-7.32 \pm 0.64 \mathrm{a}$ & $-8.30 \pm 0.51 \mathrm{a}$ & $-3.39 \pm 0.73 \mathrm{~b}$ & $0.60 \pm 0.55 \mathrm{c}$ \\
IDF & 50.852 & 112 & $-11.60 \pm 0.89 \mathrm{a}$ & $-7.53 \pm 1.14 \mathrm{~b}$ & $-10.75 \pm 0.50 \mathrm{ab}$ & $2.16 \pm 0.89 \mathrm{c}$ \\
& & & & & & \\
Site quality & & & & & & \\
Poor & 175.845 & 673 & $-12.89 \pm 0.74 \mathrm{a}$ & $-9.80 \pm 0.57 \mathrm{~b}$ & $-7.51 \pm 0.54 \mathrm{c}$ & $4.68 \pm 0.43 \mathrm{~d}$ \\
Medium & 36.003 & 195 & $-7.79 \pm 0.72 \mathrm{a}$ & $-6.70 \pm 0.77 \mathrm{a}$ & $-6.96 \pm 0.67 \mathrm{a}$ & $1.05 \pm 0.56 \mathrm{~b}$ \\
Rich & 84.384 & 84 & $-6.14 \pm 1.43 \mathrm{a}$ & $-7.07 \pm 0.96 \mathrm{a}$ & $-4.47 \pm 0.96 \mathrm{a}$ & $-0.04 \pm 0.85 \mathrm{~b}$ \\
& & & & & & \\
Stand Age & & & & & & \\
Young & 62.575 & 285 & $-9.87 \pm 0.98 \mathrm{a}$ & $-7.35 \pm 0.74 \mathrm{ab}$ & $-6.24 \pm 0.70 \mathrm{~b}$ & $4.75 \pm 0.83 \mathrm{c}$ \\
Mature & 81.984 & 384 & $-11.17 \pm 0.98 \mathrm{a}$ & $-8.63 \pm 0.76 \mathrm{ab}$ & $-7.07 \pm 0.67 \mathrm{~b}$ & $3.87 \pm 0.40 \mathrm{c}$ \\
Old-growth & 62.970 & 283 & $-12.71 \pm 1.04 \mathrm{a}$ & $-10.88 \pm 0.75 \mathrm{ab}$ & $-8.10 \pm 0.78 \mathrm{~b}$ & $1.81 \pm 0.60 \mathrm{c}$ \\
\hline
\end{tabular}




\section{Figure legends}

Figure 1. BC's biogeoclimatic zones (sensu Pojar et al. 1987). Also shown, are the locations of the three communities used for the pilot projects, Burns Lake, Sicamous, and Invermere.

Figure 2. FORECAST is the forest-growth engine of FIRST Heat. The model simulates tree growth based on potential biomass generated by the foliage through photosynthesis (central circle). Photosynthesis depends on the efficiency of leaf nitrogen, which is limited by the availability of light and nutrients. Nutrients in the ecosystem can be in different compartments (rectangles), and transfer between them following natural or anthropogenic pathways (diamonds) (modified from Kimmins et al. 1999).

Figure 3. Estimation of available $\mathrm{N}$ in FORECAST in each annual time step. Step 1: geochemical inputs were calculated, with all the forms of N lumped together. Step 2: biochemical fluxes. Step 3: Plants uptake the available N. Step 4: Soil N remaining for next time step is calculated by subtracting the remaining $\mathrm{N}$ from the soil CEC (for ammonium) or AEC (for nitrate). The $\mathrm{N}$ excess was assumed to be lost via leaching (for complete descriptions of the simulation of these processes see Kimmins et al. 1999).

Figure 4. Relative change in soil organic matter (SOM) content in two mixed conifer forests (Douglasfir, western redcedar, and western hemlock) in Sicamous: a young forest in a medium quality site (upper panel); and a mature forest in a poor quality site (lower panel). Different management control plans for three different levels of wildfire risk corresponding to maximum, intermediate and minimum interventions as recommended by FireSmart. Stand types correspond to $\mathrm{Fd} \mathrm{Cw} \mathrm{Hw}$ medium and $\mathrm{Hw} \mathrm{Cw}$ Fd poor in Table S1 (Supplemental Material).

Figure 5. Percentage of initial SOM lost after 50 years in forests of 5 different biogeoclimatic zones (Pojar et al. 1987), with two different types of management for wildfire control risk.

Figure 6. Percentage of initial SOM lost after 50 years in stands of three age classes, under two different types of management for wildfire control risk.

Figure 7. Percentage of initial SOM lost after 50 years in stands of three site qualities (measured as site index), under two different types of management for wildfire control risk.

Figure 8. Decision tree defining the hierarchy and grouping of the variables defining SOM losses.

White boxes indicate groups that contain stand types with losses above and below the $10 \%$ threshold 
and that can be further split. Green boxes are terminal nodes with all the stand types below the $10 \%$ threshold and yellow boxes are terminal nodes with all the stand types above the $10 \%$ threshold (negative values denote SOM losses). 


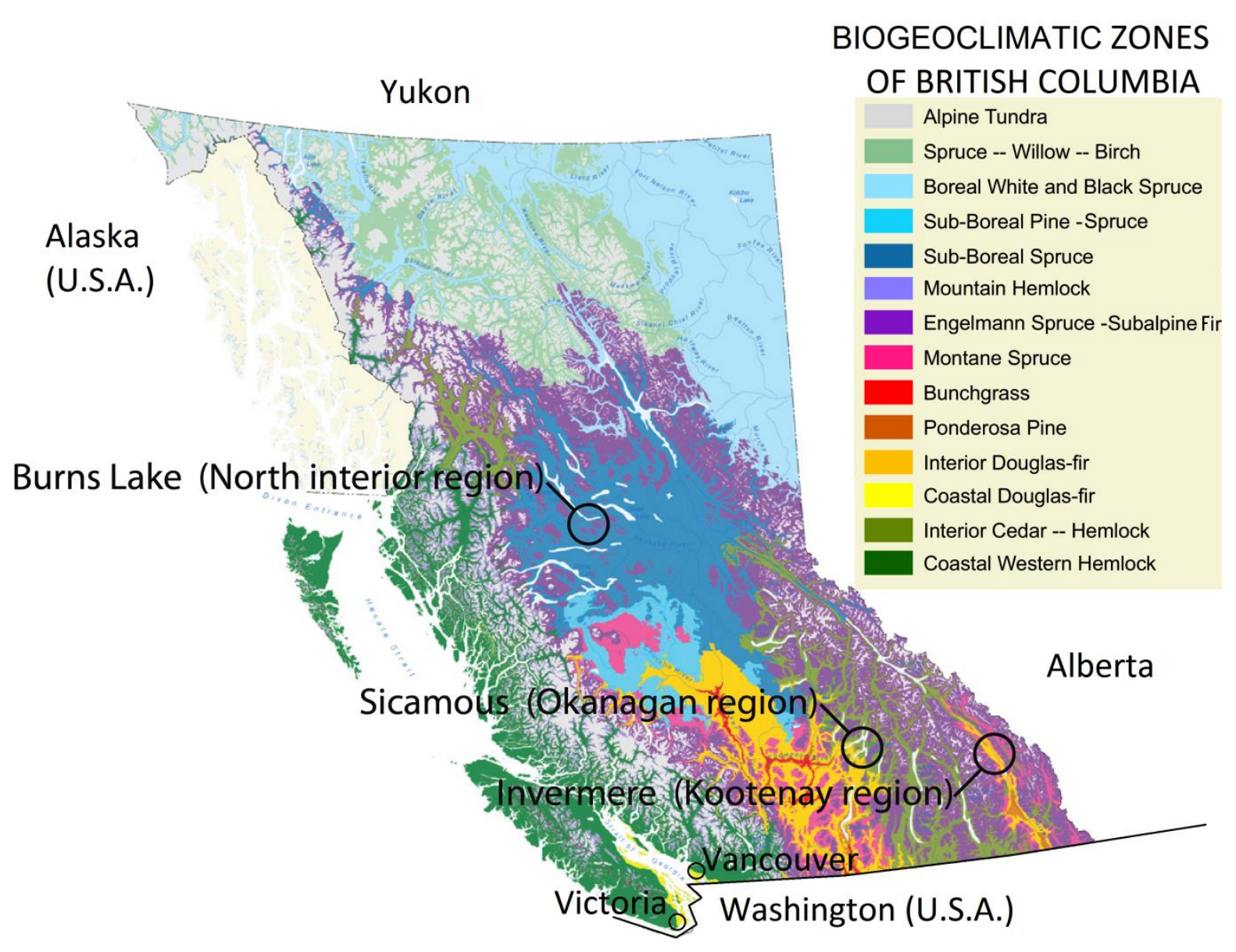

Figure 1. 


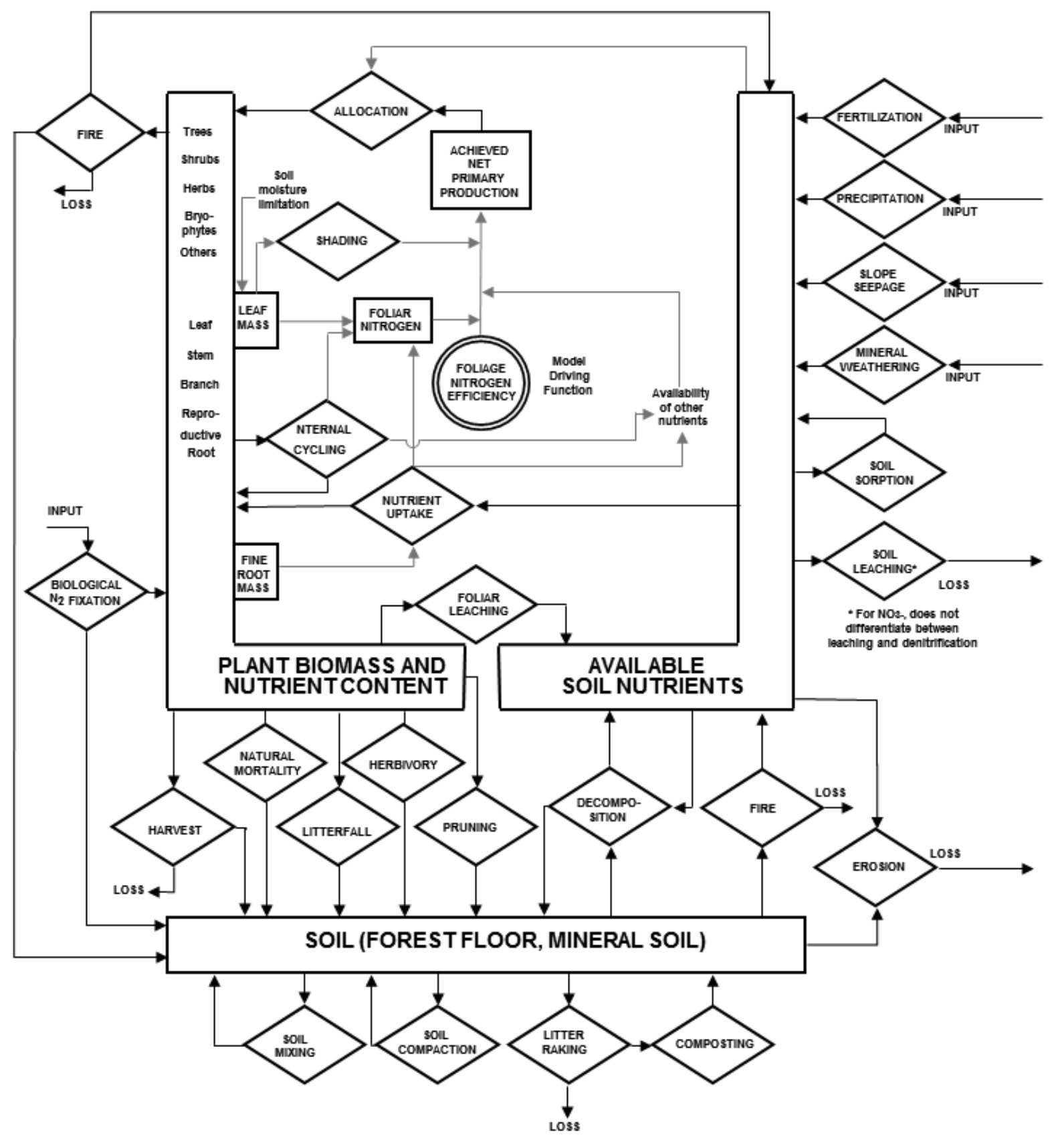

Figure 2. 


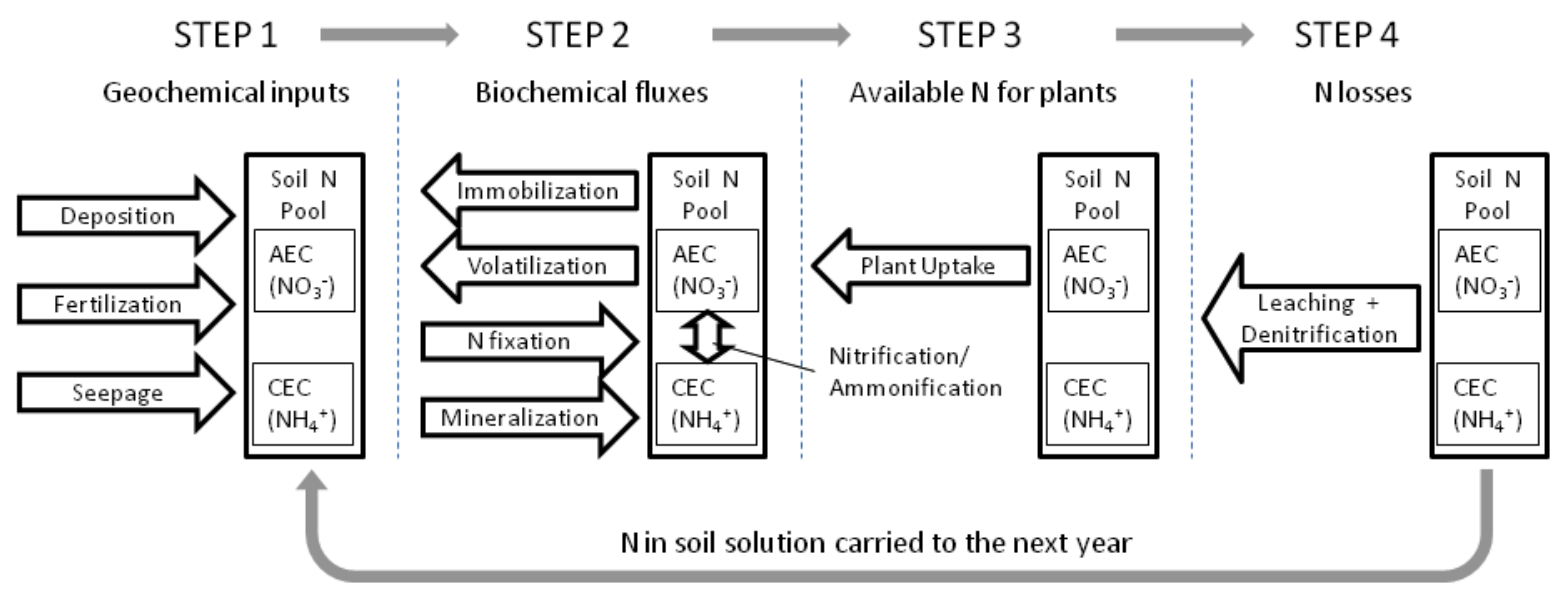

Figure 3. 


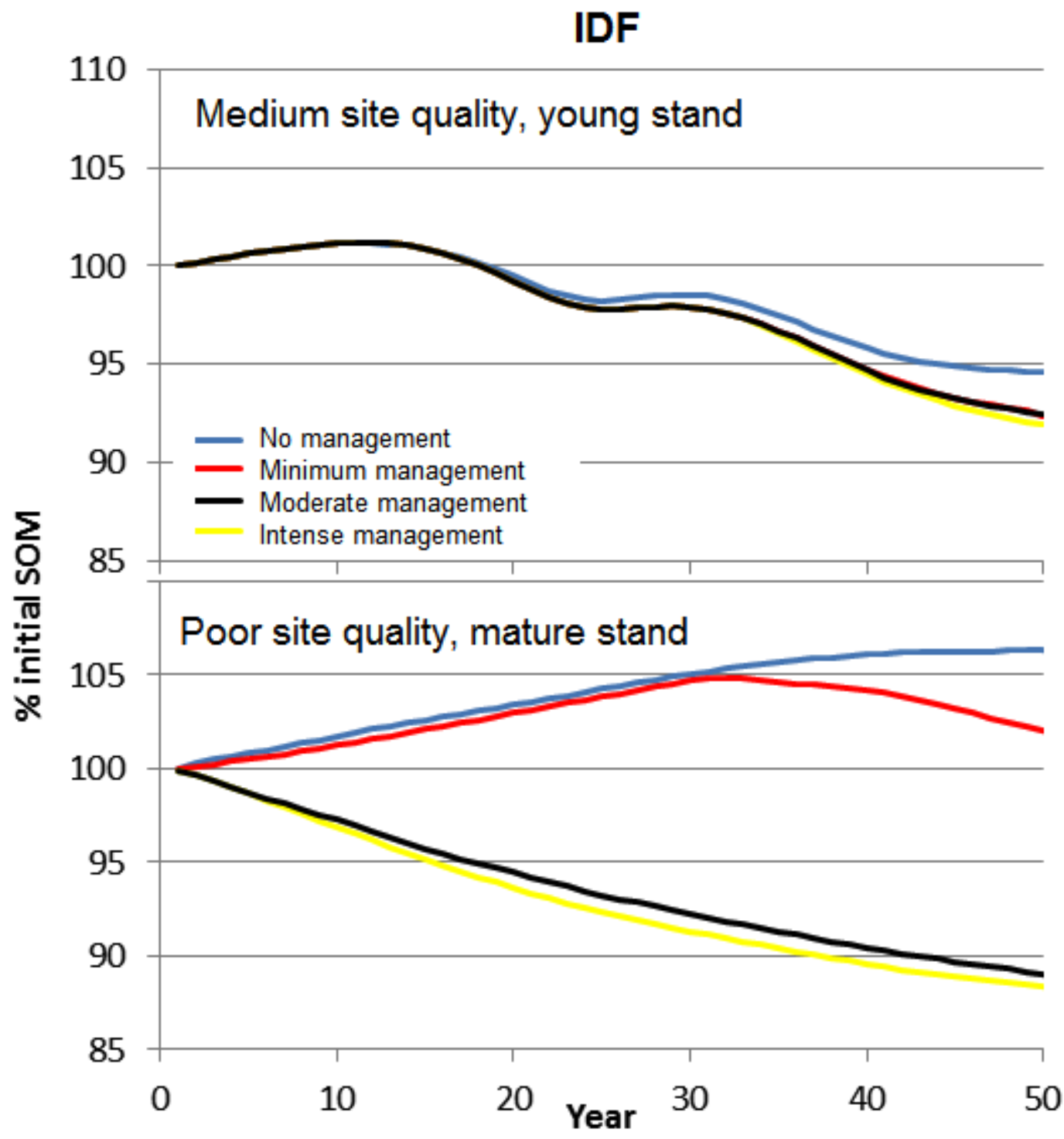

Figure 4. 


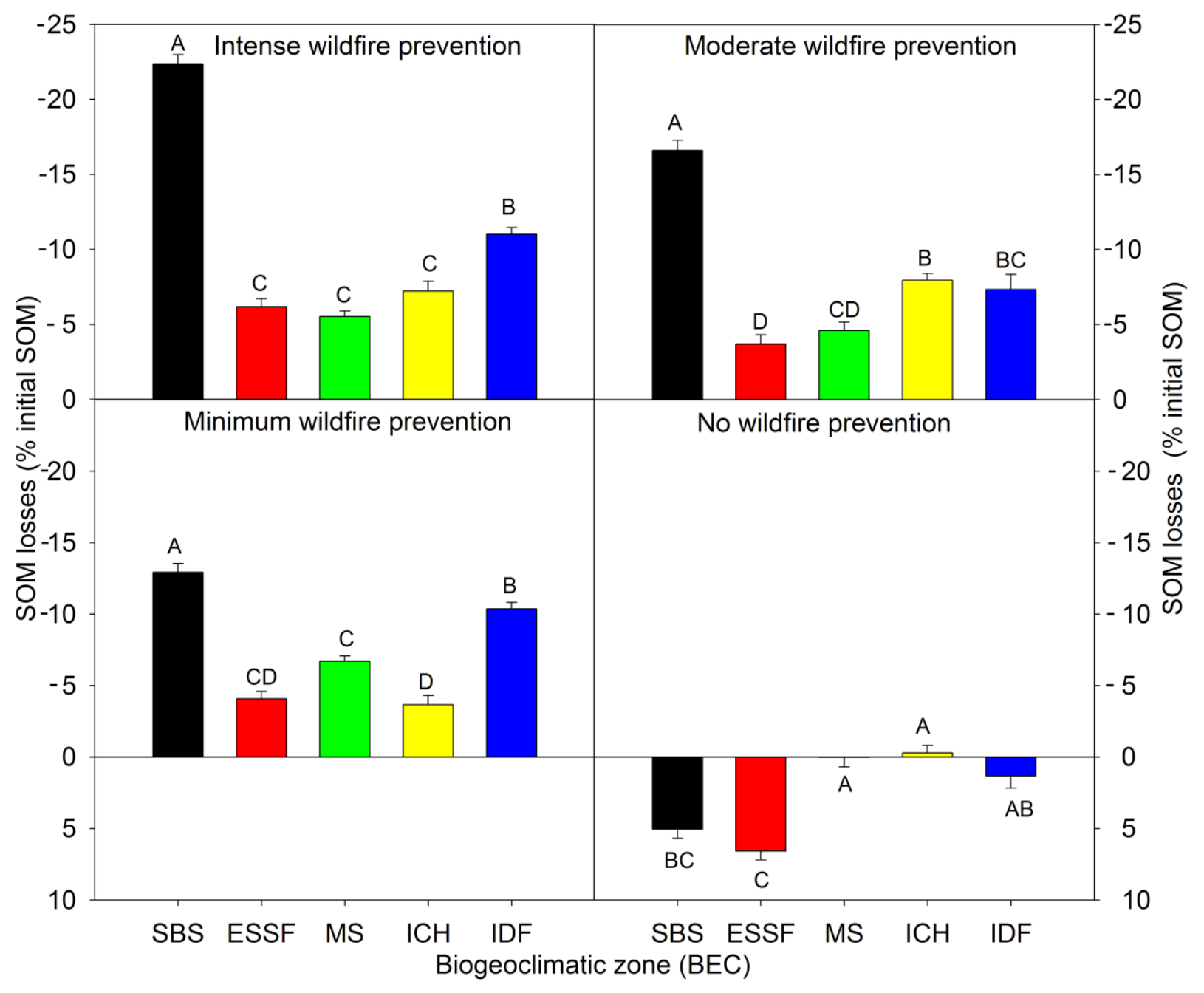

Figure 5. 


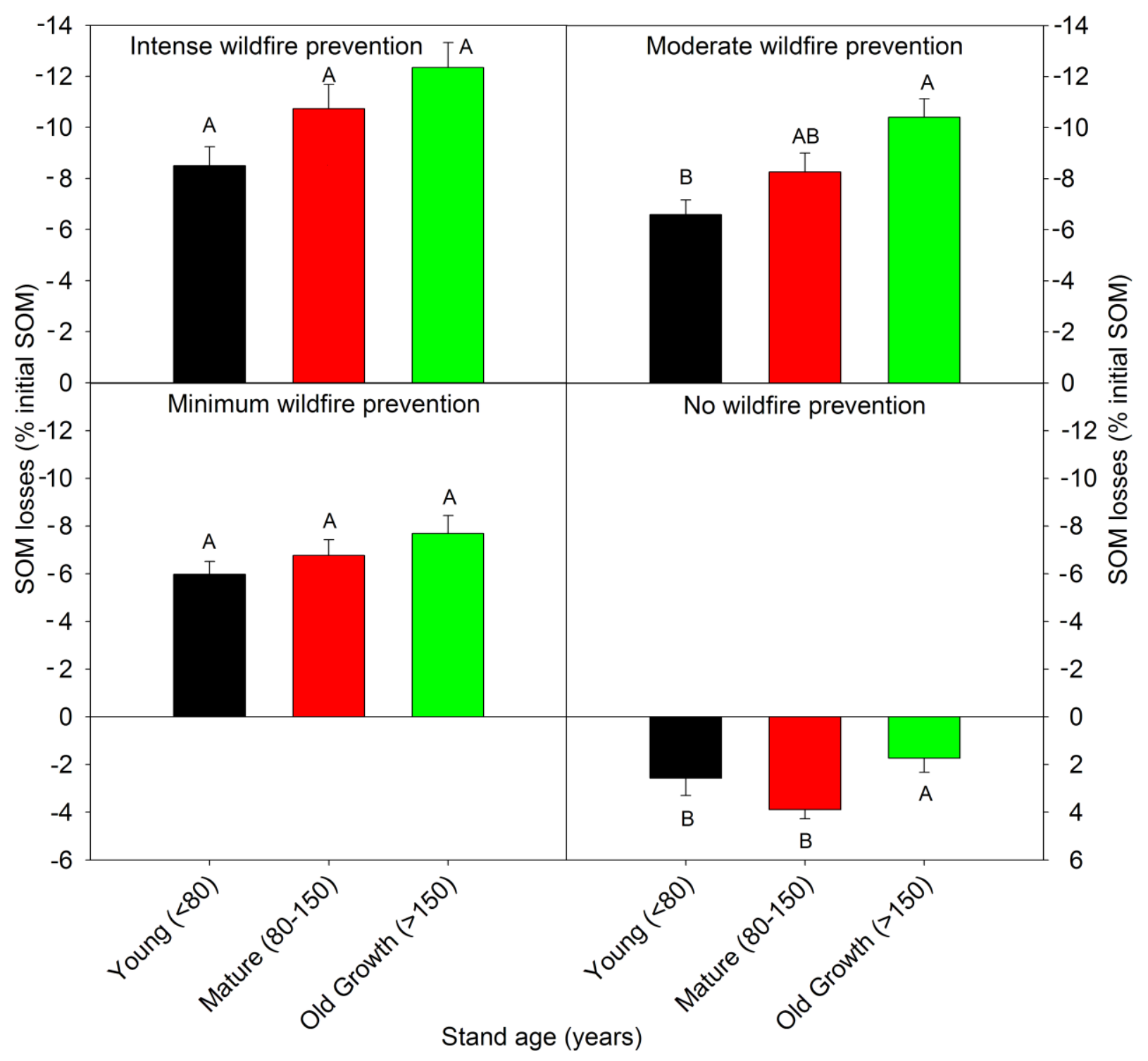

Figure 6 . 


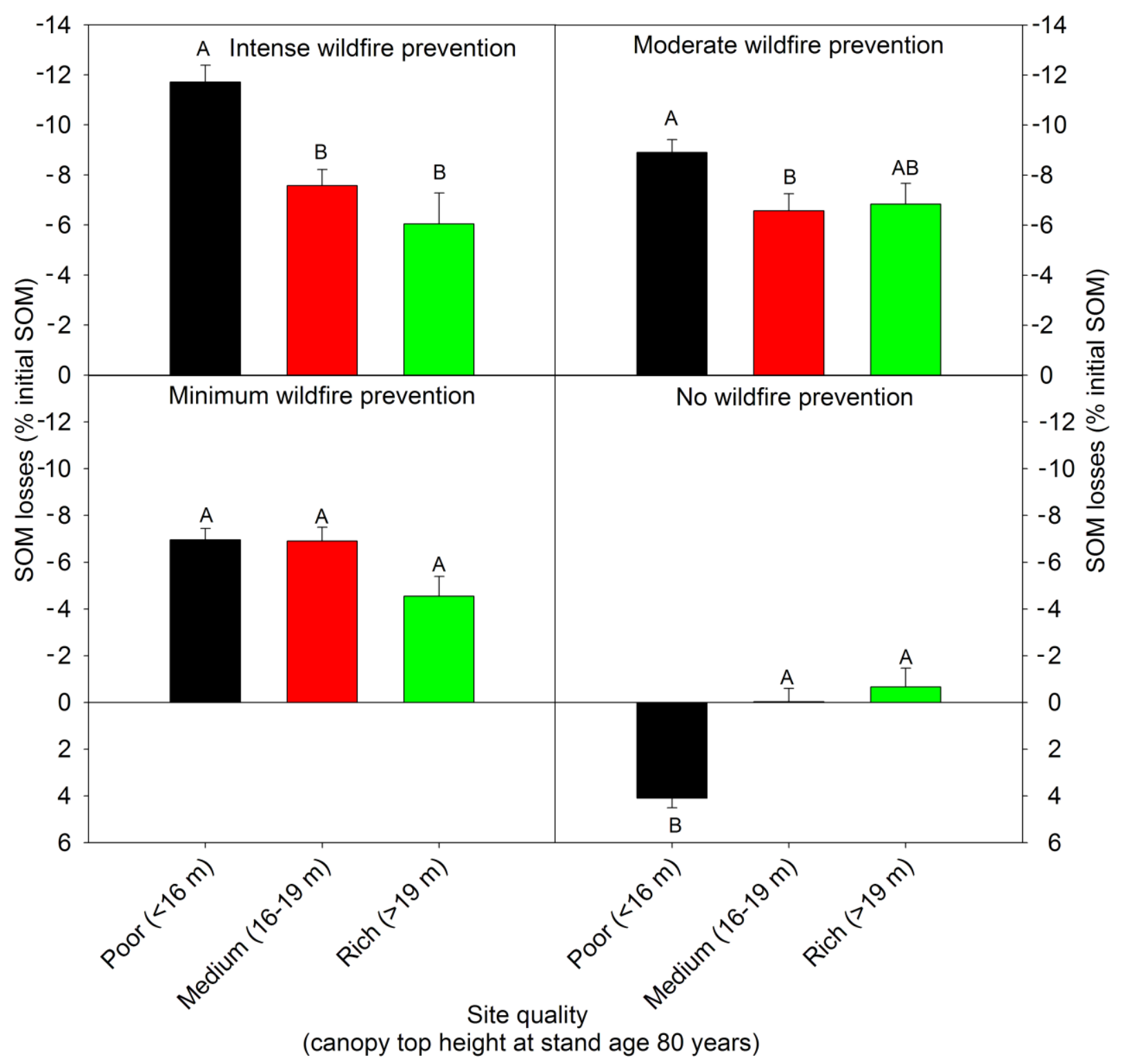

Figure 7. 


\begin{tabular}{|c|c|}
\hline $\begin{array}{c}\text { All stands } \\
\begin{array}{c}\Delta \mathrm{SOM}=-5.94 \pm 0.29 \% \\
\mathrm{~N}=952 \\
\downarrow\end{array}\end{array}$ & \\
\hline $\begin{array}{c}\text { Management } \\
\begin{array}{c}\Delta \mathrm{SOM}=-9.10 \pm 0.29 \% \\
\mathrm{~N}=714\end{array}\end{array}$ & $\begin{array}{c}\text { No management } \\
\begin{array}{c}\Delta S O M=3.53 \pm 0.35 \% \\
N=238\end{array}\end{array}$ \\
\hline \multicolumn{2}{|l|}{$\downarrow$} \\
\hline $\begin{array}{c}\text { Other BEC zones } \\
\begin{array}{c}\triangle \mathrm{SOM}=-6.46 \pm 0.24 \% \\
\mathrm{~N}=567\end{array}\end{array}$ & $\begin{array}{c}\text { SBS } \\
\Delta \mathrm{SOM}=-19.28 \pm 0.48 \% \\
\mathrm{~N}=147\end{array}$ \\
\hline \multicolumn{2}{|l|}{$\downarrow$} \\
\hline $\begin{array}{c}\text { IDF } \\
\Delta \mathrm{SOM}=-9.96 \pm 0.53 \% \\
\mathrm{~N}=84\end{array}$ & $\begin{array}{c}\text { ESSF, MS, ICH } \\
\begin{array}{c}\Delta \text { SOM }=-5.85 \pm 0.25 \% \\
N=483\end{array}\end{array}$ \\
\hline \multicolumn{2}{|l|}{$\downarrow$} \\
\hline $\begin{array}{c}\text { Other managements } \\
\begin{array}{c}\Delta \mathrm{SOM}=-11.18 \pm 0.51 \% \\
\mathrm{~N}=56\end{array}\end{array}$ & $\begin{array}{l}\text { Moderate management } \\
\qquad \begin{array}{c}\Delta \mathrm{SOM}=-7.53 \pm 1.14 \% \\
\mathrm{~N}=28\end{array}\end{array}$ \\
\hline \multicolumn{2}{|l|}{$\downarrow$} \\
\hline $\begin{array}{c}\text { Young stands } \\
\begin{array}{c}\Delta \mathrm{SOM}=-9.93 \pm 1.19 \% \\
\mathrm{~N}=16\end{array}\end{array}$ & $\begin{array}{c}\text { Other stand ages } \\
\begin{array}{c}\Delta \mathrm{SOM}=-11.68 \pm 0.52 \% \\
\mathrm{~N}=40\end{array}\end{array}$ \\
\hline \multicolumn{2}{|l|}{$\downarrow$} \\
\hline $\begin{array}{c}\text { Intense management } \\
\begin{array}{c}\Delta \mathrm{SOM}=-10.71 \pm 2.07 \% \\
\mathrm{~N}=8\end{array}\end{array}$ & $\begin{array}{c}\text { Minimum management } \\
\begin{array}{c}\Delta \mathrm{SOM}=-9.14 \pm 1.26 \% \\
\mathrm{~N}=8\end{array}\end{array}$ \\
\hline \multicolumn{2}{|l|}{$\downarrow$} \\
\hline $\begin{array}{c}\text { Poor sites } \\
\begin{array}{c}\Delta \mathrm{SOM}=-9.40 \pm 3.02 \% \\
\mathrm{~N}=4\end{array}\end{array}$ & $\begin{array}{c}\text { Medium sites } \\
\begin{array}{c}\Delta \mathrm{SOM}=-12.03 \pm 3.12 \% \\
\mathrm{~N}=4\end{array}\end{array}$ \\
\hline
\end{tabular}

Figure 8.

This work is licensed under the Creative Commons Attribution-NonCommercial-NoDerivatives 4.0 International License. To view a copy of this license, visit http://creativecommons.org/licenses/by-ncnd/4.0/ or send a letter to Creative Commons, PO Box 1866, Mountain View, CA 94042, USA. 